\title{
Applying the mental models framework to carbon monoxide risk in northern Mexico
}

\author{
Heather C. Galada, ${ }^{1}$ Patrick L. Gurian, ${ }^{1}$ Veronica Corella-Barud, ${ }^{2}$ \\ Frank G. Pérez, ${ }^{3}$ Gilberto Velázquez-Angulo, ${ }^{4}$ Susana Flores, ${ }^{2}$ and \\ Teresa Montoya ${ }^{2}$
}

Suggested citation Galada HC, Gurian PL, Corella-Barud V, Pérez FG, Velázquez-Angulo G, Flores S, Montoya T. Applying the mental models framework to carbon monoxide risk in northern Mexico. Rev Panam Salud Publica. 2009;25(3):242-53.

ABSTRACT Objectives. Low-income residents of northern Mexico rely on unvented heaters during the winter, a practice that puts them at elevated risk for carbon monoxide intoxication. The goal of this study is to develop a communication protocol for carbon monoxide intoxication risks among the primarily low socioeconomic status population of Ciudad Juárez, Chihuahua, Mexico.

Methods. The mental models risk communication approach was used to identify important gaps in public understanding. This approach consists of step-by-step assessment of information needs and effectiveness of risk communication efforts by using interviews and surveys.

Results. The mental models process uncovered a key technical misunderstanding, the subject population's belief that carbon monoxide can be seen or smelled, which may result in a risk-prone behavior: failure to use a carbon monoxide detector. A communication protocol was designed to address this and other knowledge gaps, and it produced significant improvements in subjects' knowledge in a pretest/posttest evaluation.

Conclusions. The mental models process was successful in developing a communication instrument capable of improving knowledge in the subject population. Future research needs include assessing the extent to which this instrument succeeds in changing behavior and reducing the risk of carbon monoxide intoxication. Future interventional efforts may focus on encouraging people to use carbon monoxide detectors.

Key words Carbon monoxide, communication, risk management, Mexico.

1 Civil, Architectural, and Environmental Engineering, Drexel University, Philadelphia, Pennsylvania, United States of America. Send correspondence and reprint requests to: Patrick Gurian, Civil, Architectural, and Environmental Engineering, Drexel University, 3141 Chestnut Street, Philadelphia, Pennsylvania, United States of America; telephone: 215-895-2889; e-mail: pgurian @drexel.edu

2 Center for Environmental Resource Management, University of Texas at El Paso, El Paso, Texas, United States of America.

3 University of Texas at El Paso, El Paso, Texas, United States of America.

4 Department of Civil and Environmental Engineering, Universidad Autónoma de Ciudad Juárez, Ciudad Juárez, Chihuahua, México.
Carbon monoxide (CO) causes 70000 emergency room visits and thousands of deaths per year in North America (1). More than half of all recorded fatal poisonings worldwide are believed to be due to CO poisoning (2). In the United States alone, more than 2000 people die annually from CO intoxication (3). Besides the threat of death, disabling cognitive and neuropathological sequelae are associated with harmful levels of $\mathrm{CO}(4,5)$.

$\mathrm{CO}$ intoxication is an especially serious problem in regions with low-income res- idents, who cannot afford vented heating systems, and with climates cold enough to require indoor heating, such as Ciudad Juárez, Mexico. The per capita risk for $\mathrm{CO}$ poisoning for Ciudad Juárez is about six times that of the United States (6). A previous study found that two-thirds of households with unvented heaters have CO levels exceeding the World Health Organization's health guidelines, which means tens of thousands of people in Ciudad Juárez are exposed to harmful concentrations (6). According to Diario de Juárez, 167 Juarenses died due to CO poi- 
soning, and more than 1300 were intoxicated between 1992 and 2004 (7). Of these intoxications, $59 \%$ occurred due to gas heaters and $18 \%$ were due to wood-burning heaters or grills (8).

An effective risk communication strategy is needed to inform the population of the risk and motivate them to take appropriate actions. This goal of developing a prescriptive risk-communication instrument presents substantial challenges. There are a variety of methods to mitigate the dangers of $\mathrm{CO}$ poisoning, with some being more effective than others and some being more or less expensive. One clearly wants the population to benefit from vented heating systems, but many households are unable to afford these systems. Rather than advocate a theoretically effective method that would not realistically be implemented, this study seeks to identify a method that would realistically be implemented. Thus, the study had the goal of not only assessing the target population's knowledge of the risk but also their attitudes toward potential risk mitigation strategies.

While previous studies have investigated $\mathrm{CO}$ exposures and risk factors in this region of Mexico (8-10), there are no previous studies assessing public communication needs or evaluating different risk communication strategies. Although it has been well established that improved knowledge alone does not necessarily lead to behavioral change (11) in many issues involving complex technological risk, adequate understanding of the risk is a prerequisite for making appropriate behavioral changes (at a minimum one must know which behaviors are effective at reducing risk). This study used the mental models approach to develop an effective risk communication protocol. The mental models approach (12) seeks to combine expert and public knowledge to generate a health communication protocol that provides the required information and is accessible to the target population.

The mental models method has four phases (Figure 1). First, a review of the relevant scientific literature and interviews with experts are conducted to develop a summary of expert knowledge. Second, semistructured interviews are conducted with members of the general public eliciting baseline public knowledge and conceptual understanding about the technical issues the protocol seeks to address. The information gathered allows

FIGURE 1. Mental models risk communication framework

Phase 1

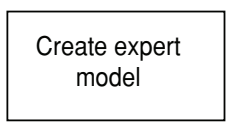

Phase 3

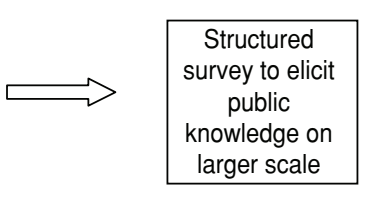

Phase 4

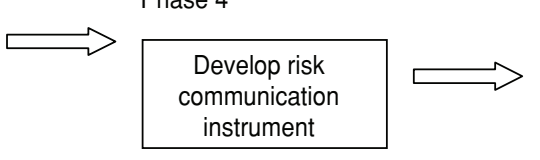

for the creation of two conceptual models: one expert model and one lay model. These models are then compared to identify key discrepancies between the public and expert understanding. In the third step, a structured survey instrument is administered to more rigorously quantify the baseline (preintervention) prevalence of different gaps in public understanding. In the fourth step, a communication protocol is drafted to address knowledge gaps that occur frequently (as indicated by the baseline survey) and that influence important decisions by the public. The performance of the protocol is evaluated empirically for its ability to effectively communicate with the target audience and is revised as necessary (12).

An array of mental model communication studies have been performed, addressing a wide range of risks, including radon $(13,14)$, electromagnetic fields (15-17), climate change (18), nuclear power (19), 5 adolescent smoking (20), chemical risks in the workplace (21), wildland fires (22), and drugs (23). In only four of these previous studies have the risk communication protocols developed using the mental models approach been empirically assessed with a pretest and posttest analysis. The first of these, conducted by Maharik and Fischhoff (19), involved developing mental models of knowledge and feelings about

\footnotetext{
5 Maharik M. Public perceptions of the risks of an unfamiliar technology: the case of using nuclear energy sources for space missions [ $\mathrm{PhD}$ dissertation]. Pittsburgh: Carnegie Mellon University; 1992.
}

Phase 2
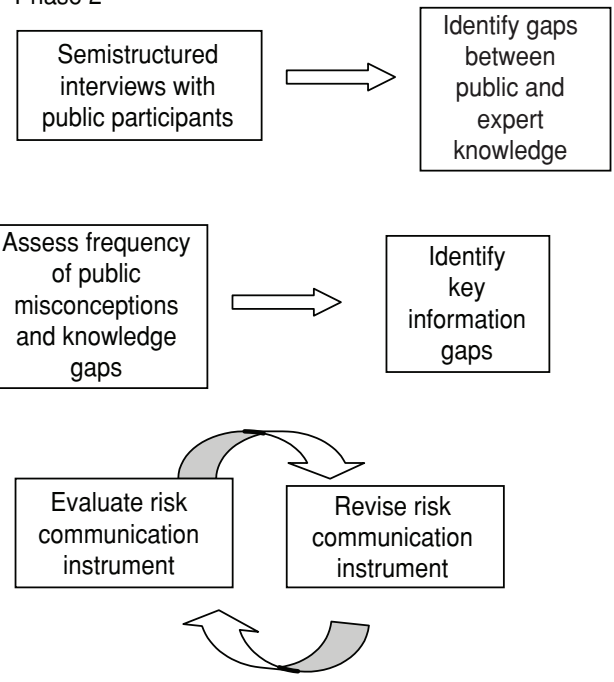

using nuclear energy sources for space missions. Subjects who read a brochure developed following the mental models approach demonstrated better knowledge than subjects who read an existing brochure developed by technical experts at the National Aeronautics and Space Administration. ${ }^{5}$

The second mental models study that used a pretest and posttest was performed by Downs et al. ${ }^{6}$ and examined HIV and AIDS expert and adolescent knowledge gaps (as described by Morgan et al. (12)). The posttest compared those who read the series of brochures designed following the mental model procedure, those who read the best existing material, and those who read nothing. Those who read the brochures developed according to the mental model procedure did best on the posttest $(p<0.05)$.

The third pretest and posttest study researched knowledge of range dependency of magnetic fields from highvoltage power lines and evaluated the effectiveness of "refining laypeople's knowledge of this relationship" (17). A brief tutorial about magnetic fields was given after the pretest, and 24 hours later a posttest was administered that contained an additional knowledge measure and demographic questions. Significant

\footnotetext{
6 Downs JS, Fischhoff B, Murray PJ, White JP, Bruine de Brun W, Palmgren C. Behavioral and biological outcomes of a mental models intervention for decreasing sexually transmitted diseases among adolescent females [unpublished]. Pittsburgh: Carnegie Mellon University; 1998.
} 
improvements in knowledge were found on the posttest.

Hampson et al. (14) used a pretest and posttest to evaluate the effectiveness of a brochure developed following the mental models approach to improve understanding of the synergistic effects of radon and cigarette smoking. Despite reading an informational brochure, the subjects' risk perception ratings of three hazards showed no perception of synergy between smoking and radon risk.

In this study, the mental models framework is used as a means to accomplish three goals: (1) to identify an appropriate behavioral change to reduce CO intoxication risk, (2) to identify the knowledge gaps that might hinder adoption of this behavioral change, and (3) to develop and test a risk communication protocol for addressing these knowledge gaps. Evaluating the extent of behavioral change achieved by the risk communication protocol is a key research need but was not addressed within the scope of this effort.

\section{MATERIALS AND METHODS}

The implementation of each of the four components of the mental models risk communication methodology (summarized in Figure 1) is described below. Further details of the project, including copies of survey forms used, are provided in the project final report, which is available online at http://coproject juarez.wikispaces.com. Interviews were conducted by students at the Universidad Autónoma de Ciudad Juárez, who were trained by the investigators. Institutional Review Board approval was obtained for all activities involving the participation of human subjects.

\section{Expert model development}

The first phase of the expert model development consisted of a review of the literature on $\mathrm{CO}$ poisoning to identify the mechanisms and effects of $\mathrm{CO}$ intoxication. The literature review also identified common risk factors and risk mitigation strategies. To address issues specific to this region, two interviews were conducted with officials from local agencies responsible for emergency response and public education for $\mathrm{CO}$ risk (Ciudad Juárez and El Paso Fire Departments). An expert mental model was developed that included elements from the interviews and the literature. An influ- ence diagram, in which boxes indicate key elements or concepts and arrows represent causal links or associations, was used to visually depict this information (Figure 2).

\section{Lay mental model development}

Some general understanding of participants' attitudes and practices was gained through three focus groups conducted as part of a previous project (6). Information from the focus groups was not analyzed here because of the small sample size $(n=3)$ and because it is difficult to identify individual knowledge gaps in group settings.

In this study, individual interviews were conducted with 25 participants who were selected from neighborhoods on the Ciudad Juárez periphery to represent the target population. A sample size of 25 was chosen to provide a high probability that all the beliefs commonly present in the population at large will be found in the sample. For example, if a particular belief or attitude occurs in at least $10 \%$ of the population, then it is 93\% likely that at least one of the interview subjects will have this belief or attitude. These interviews serve to identify important attitudes and beliefs in the subject population and thereby inform the development of the baseline survey that more systematically and rigorously documents the frequency of different beliefs in the subject population.

The interviews lasted about $30 \mathrm{~min}$ utes and took place in public government or social service locations, where people have to wait an extended time for a service (car registration offices, local clinics). A 50 peso gift card was given to each respondent for participating. Interviewers were provided with a list of questions designed to elicit knowledge in a nondirective fashion. This openended approach provides an assessment of knowledge that is readily accessible by members of the public. There may be additional information that subjects could recall or even surmise when given prompts. However, this approach is useful as an initial, exploratory effort to understand the level of knowledge and to identify topics needing additional research (24). Questions were developed to assess participants' knowledge of information considered important based on the expert model. Example questions include the following: (1) What is CO? (2)
Can you tell me where CO comes from? (3) What can CO do to you? (4) How can you detect the presence of $\mathrm{CO}$ ?

The expert model was used to provide a framework for interpreting the interview. Subjects' responses were reviewed and the frequency with which respondents correctly identified different aspects of the expert model was encoded on the influence diagram representation of the expert model (Figure 2). For example, each time wood heaters were mentioned as a source of $\mathrm{CO}$ (question 2 above) it was encoded in the appropriate location of the expert model influence diagram (in this case, the fifth box from the upper right hand corner of Figure 2). Elements of the diagram that were substantively important-that is, related to behavioral decisions affecting $\mathrm{CO}$ riskand that had low levels of public understanding were flagged for more systematic follow-up during the subsequent baseline survey.

\section{Baseline survey}

While the interview process elicited potentially important knowledge gaps, a follow-up survey with a larger sample size was used to quantify the baseline (preintervention) frequency with which these knowledge gaps are found in the subject population. This survey of baseline knowledge used a 51-item questionnaire, which was administered orally to each participant individually. Forty-three questions were related to knowledge about $\mathrm{CO}$ and its health effects: how people heat their homes in the winter, the precautions they already take, and information about whom they go to if they have problems related to $\mathrm{CO}$ poisoning. Eight questions addressed information to generate a better understanding of the target population's background and socioeconomic status, including questions addressing respondents' educational attainment, income, and other socioeconomic variables.

A total sample size of 150 was targeted to reduce sample variability in estimated frequencies of responses to $\pm 8 \%$ (for $\alpha=$ 0.05 , based on a two-sided confidence interval for proportion of responses to a given question). The actual sample size obtained was 149. This size is sufficient to separate widespread misconceptions from infrequent ones and thereby identify the most important elements of subsequent risk communication protocols. 
FIGURE 2. Expert mental model, with number of laypersons (of 25) who mentioned topic in initial survey shown in parentheses. Potential knowledge gaps considered less critical are bold and those judged more critical are bold, italicized, and underlined

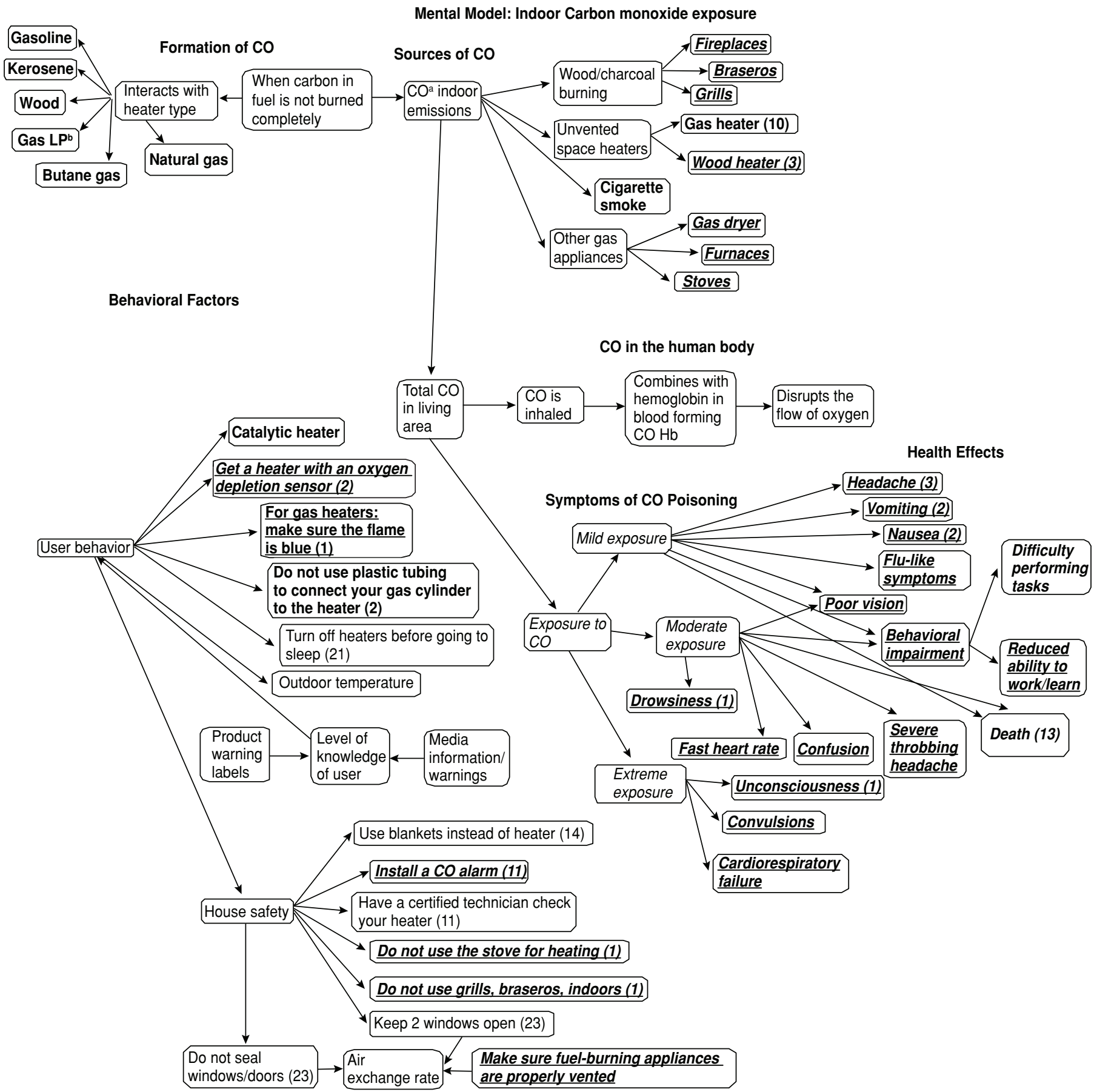

a $\mathrm{CO}$, carbon monoxide.

${ }^{b}$ LP, liquefied petroleum.

A convenience sampling approach was used in which participants were recruited at shopping centers and at government and social service organization offices. The results should not be considered representative of all of Ciudad Juárez but did represent individuals who would be reached by an interven- tional campaign using these same locations. Convenience samples are widely used in risk communication research as the goal is to identify the most important issues (rather than to quantify differences in rates among groups as in an epidemiological study). The data were analyzed using SPSS software (SPSS,
Chicago, Illinois, United States) and Excel software (Microsoft, Redmond, Washington, United States). Differences in the frequencies of different survey responses were tested for significance by using a $\chi^{2}$ test of proportions, and $p$ values below 0.05 were considered statistically significant. 


\section{Risk communication instrument development and evaluation}

A comic-book style pamphlet was designed to address the knowledge gaps identified by the mental models process. The story line built on Rogers' suggestion that opinion leaders are an effective part of the health campaign diffusion process (11); as such, the story line demonstrated the important role that more knowledgeable individuals can play in disseminating health information. The most knowledgeable character first disseminates her knowledge to a partially informed character. Then both characters provide information to a lessinformed character.

The performance of this risk communication instrument was evaluated by members of the target population. Inclusion of individuals from the targeted group is crucial to successful campaigns because researchers are culturally different from those they typically hope to reach via health campaigns (25). The initial evaluation consisted of semistructured think-aloud interviews with 10 individuals and also two focus groups with four and seven participants. These results were used in refining the comic book and the evaluation survey but are not reported here because of the unstandardized nature of these exploratory ef- forts. The comic book was edited, and the final version was evaluated empirically using a survey of residents of Ciudad Juárez that assessed knowledge about $\mathrm{CO}$ and willingness to make changes to combat $\mathrm{CO}$ poisoning before and immediately after participants read the comic book. This survey was administered orally to each participant individually. Differences in the frequency of responses between the pretest and posttest were compared to determine the success of the pamphlet in relaying important information to the public. A sample size of 100 was used, which provides a better than $80 \%$ chance of detecting a difference in response rates of $20 \%$ between the pretest and the posttest $(\alpha=0.05$, two-tailed test of proportions) (26).

\section{RESULTS}

\section{Expert and lay models}

The comparison between the public and expert mental models identified several potential knowledge gaps. The numbers in parentheses in Figure 2 indicate the number of subjects who mentioned that topic in the interviews (out of 25). Bold type is used to indicate less critical potential knowledge gaps; bold, italicized, and underlined type is used for more critical knowledge gaps. A sum- mary of major results from the semistructured interviews is also provided in the second column of Table 1. A minority of subjects mentioned wood heaters and cigarette smoke as sources of $\mathrm{CO}$. These items were classified as knowledge gaps because only a minority of subjects mentioned each source. Cigarette smoke was judged to be a less critical knowledge gap since there are no reports of acutely fatal intoxication from this source. Ten of 25 participants mentioned gas heaters as a source of $\mathrm{CO}$, and 3 of 25 noted that wood heaters could produce $\mathrm{CO}$. Lack of knowledge of the sources of $\mathrm{CO}$ was judged to be a potentially severe knowledge gap because these items have been associated with intoxication incidents (8), and knowledge of CO sources was flagged as an item for follow-up on the baseline survey (see below).

Just over half the participants (13 of 25) indicated that $\mathrm{CO}$ exposure could be fatal. The fact that a substantial minority of respondents did not address this information was judged to be potentially severe, as knowledge of the consequences might help to motivate behavioral changes. Only a small number of respondents mentioned less severe symptoms, such as drowsiness ( 1 of 25), headache (3 of 25), and nausea (2 of 25). These knowledge gaps were judged to be potentially critical for two reasons: (1) greater awareness

TABLE 1. Knowledge gaps identified and evaluated throughout mental models process, Mexico

\begin{tabular}{|c|c|c|c|c|c|}
\hline Element & $\begin{array}{c}\text { Semistructured interview, } 2005 \\
\text { (Figure 2) }^{\mathrm{a}}\end{array}$ & $\begin{array}{l}\text { Baseline survey, 2005-2006 } \\
\text { (Table 3) }\end{array}$ & Priority & $\begin{array}{l}\text { Pretest, 2006-2007 } \\
\text { (Table 5) }\end{array}$ & $\begin{array}{l}\text { Posttest, 2006-2007 } \\
\text { (Table 5) }\end{array}$ \\
\hline $\mathrm{CO}^{\mathrm{b}}$ detector & 11 of 25 knowledgeable & $\begin{array}{l}\text { Misconceptions about need for } \\
\text { alarm (questions } 1 \text { and 2) and } \\
\text { cost (question 11) }\end{array}$ & Highest priority & $\begin{array}{l}\text { Moderate knowledge } \\
\text { (questions 12, 20-23) }\end{array}$ & $\begin{array}{l}\text { Good improvement } \\
\text { (questions 12, 20-23) }\end{array}$ \\
\hline $\begin{array}{l}\text { Nonacute } \\
\text { symptoms }\end{array}$ & $\begin{array}{l}2 \text { of } 25 \text { knowledgeable of } \\
\text { vomiting, nausea; } 3 \text { of } 25 \\
\text { knowledgeable of headache; } \\
\text { others not mentioned }\end{array}$ & $\begin{array}{l}\text { A minority are unaware of } \\
\text { nonacute symptoms } \\
\text { (questions 5-7) }\end{array}$ & Moderate priority & $\begin{array}{l}\text { Good knowledge } \\
\text { (questions 15-18) }\end{array}$ & $\begin{array}{l}\text { Improvement } \\
\text { (questions 15-18) }\end{array}$ \\
\hline Sources & $\begin{array}{l}10 \text { of } 25 \text { knowledgeable of gas } \\
\text { heater, } 3 \text { of } 25 \text { knowledgeable } \\
\text { of wood heater, others not } \\
\text { mentioned }\end{array}$ & $\begin{array}{l}\text { Misconceptions about electric } \\
\text { heaters; most respondents } \\
\text { aware of major sources } \\
\text { (questions 13-16) }\end{array}$ & Low priority & $\begin{array}{l}\text { Moderate knowledge } \\
\text { (questions 2-10) }\end{array}$ & $\begin{array}{l}\text { Improvement } \\
\text { (questions 2-10) }\end{array}$ \\
\hline $\begin{array}{l}\text { Oxygen depletion } \\
\text { sensors }\end{array}$ & 2 of 25 knowledgeable & $\begin{array}{l}\text { Misconceptions about price } \\
\text { (question 12) }\end{array}$ & Moderate priority & $\begin{array}{l}\text { Moderate knowledge } \\
(67 \% \text { question } 24)\end{array}$ & $\begin{array}{l}\text { Improvement (88\% } \\
\text { question 24) }\end{array}$ \\
\hline Death & 13 of 25 knowledgeable & $\begin{array}{l}\text { Most respondents } \\
\text { knowledgeable, only } 11 \% \\
\text { unaware } \\
\text { (question 10) }\end{array}$ & Low priority & $\begin{array}{l}\text { Good knowledge ( } 98 \% \\
\text { question 19) }\end{array}$ & $\begin{array}{l}\text { Small improvement } \\
\text { (99\% question 19) }\end{array}$ \\
\hline
\end{tabular}

a See figure and tables indicated in parentheses for question numbers.

${ }^{\mathrm{b}} \mathrm{CO}$, carbon monoxide. 
of these symptoms might aid in the detection of nonacute exposures, which may still have substantial negative impacts on health, and (2) detection of nonacute exposures may allow for the exposure to be reduced or eliminated before more serious symptoms develop. These potential knowledge gaps were flagged for follow-up during the baseline survey (described below).

Many laypersons identified safety measures during the interviews (although that does not mean these practices were followed). Twenty-three of the 25 participants knew to keep windows open and not to seal them. This practice was not judged to be a knowledge gap, given the high percentage of respondents who mentioned this item. No respondents explicitly mentioned venting appliances as a precautionary measure, but this knowledge of the importance of venting is embedded in understanding the importance of not sealing windows and doors; therefore, this item was not judged to be a priority knowledge gap. None of the interviewees mentioned how $\mathrm{CO}$ binds with hemoglobin. This potential gap was judged to be less critical, as such fundamental causal understanding may not be necessary for individuals to be able to protect themselves from this risk.

\section{Baseline survey}

Table 2 summarizes the demographic information from the baseline survey: $25.5 \%$ of the respondents were females, and $73.8 \%$ were males. The reasons for the lack of gender balance are not fully understood. It may be that males are more likely to be in the venues used for

TABLE 2. Demographic data obtained from baseline survey and pretest and posttest evaluation, Mexico

\begin{tabular}{|c|c|c|c|c|}
\hline \multirow[b]{3}{*}{ Parameter } & \multicolumn{4}{|c|}{ Participants } \\
\hline & \multicolumn{2}{|c|}{$\begin{array}{c}\text { Baseline survey } \\
2005-2006 \\
(n=149)\end{array}$} & \multicolumn{2}{|c|}{$\begin{array}{c}\text { Pretest/posttest } \\
\text { evaluation } \\
2006-2007 \\
(n=100)\end{array}$} \\
\hline & $\%$ & $95 \% \mathrm{Cl}$ & $\%$ & $95 \% \mathrm{Cl}$ \\
\hline \multicolumn{5}{|l|}{ Gender } \\
\hline Female & 25.5 & $18.5-32.5$ & 43.0 & $33.3-52.7$ \\
\hline Male & 73.8 & $66.8-80.9$ & 57.0 & $47.3-66.7$ \\
\hline Miscoded & 0.7 & $0.2-2$ & & \\
\hline \multicolumn{5}{|l|}{ Education } \\
\hline Elementary school & 24.2 & $17.3-31.0$ & 28.0 & $19.2-36.8$ \\
\hline Middle school & 32.2 & $24.7-39.7$ & 33.0 & $23.8-42.2$ \\
\hline High school & 19.5 & $13.1-25.8$ & 14.0 & $7.2-20.8$ \\
\hline College & 18.1 & $11.9-24.3$ & 22.0 & $13.9-30.1$ \\
\hline Other & 5.4 & $1.7-9.0$ & 1.0 & $0.2-5.4$ \\
\hline No answer & 0.7 & $0.2-2.0$ & 2.0 & $0.6-7.0$ \\
\hline \multicolumn{5}{|l|}{ Age (years) } \\
\hline$<20$ & 6.0 & $2.2-9.9$ & 11.0 & $4.9-17.1$ \\
\hline $20-29$ & 40.3 & $32.4-48.1$ & 45.0 & $35.2-54.8$ \\
\hline $30-39$ & 26.8 & $19.7-34.0$ & 28.0 & $19.2-36.8$ \\
\hline $40-49$ & 18.1 & $11.9-24.3$ & 8.0 & $2.7-13.3$ \\
\hline $50-59$ & 7.4 & $3.2-11.6$ & 4.0 & $1.6-7.8$ \\
\hline$\geq 60$ & 0.7 & $0.2-2$ & 4.0 & $1.6-7.8$ \\
\hline
\end{tabular}

subject recruitment or were more likely than females to undertake a response when present in mixed-gender groups. Educational backgrounds varied, with $24.2 \%$ of the participants having completed only elementary school, $32.2 \%$ middle school, $19.5 \%$ high school, and $18.1 \%$ college. The sample had good representation of individuals below 30 years of age $(46.3 \%)$ but was less representative of older individuals $(0.7 \%$ of subjects were 60 or older).

Figure 3 shows the proportion of respondents using different appliances that generate CO. Most participants (79.2\%) were exposed to one or more $\mathrm{CO}$ risk factors, with the majority $(63.1 \%)$ being exposed to gas heaters. About half (46.3\%) of the respondents are exposed to the risk of CO through the use of a stove, $10.7 \%$ through the use of manufactured wood heaters, and $22.8 \%$ through improvised wood heaters known as braseros.

Important misconceptions were identified by the survey, as shown in Table 3, with the most noteworthy being that $53.0 \%$ of respondents mistakenly believed that $\mathrm{CO}$ can be detected by smell

FIGURE 3. Survey respondents' exposure to risk factors, Mexico, 2005-2006

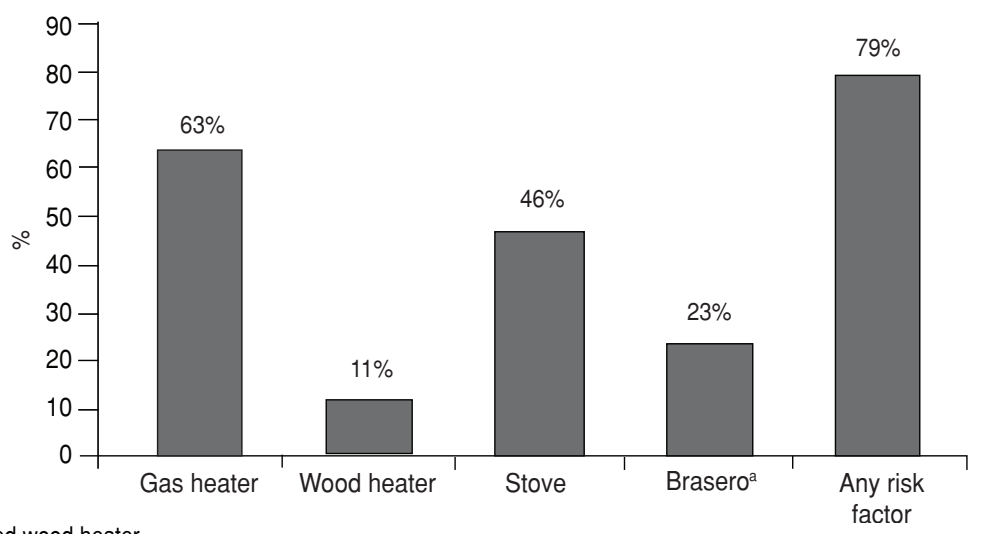

a Improvised wood heater. 
TABLE 3. Selected baseline survey results $(n=149)$, Mexico, 2005-2006

\begin{tabular}{|c|c|c|c|c|c|c|}
\hline \multirow[b]{2}{*}{ Fact } & \multicolumn{2}{|c|}{$\begin{array}{l}\text { Answered } \\
\text { correctly }\end{array}$} & \multicolumn{2}{|c|}{$\begin{array}{l}\text { Answered } \\
\text { incorrectly }\end{array}$} & \multicolumn{2}{|c|}{$\begin{array}{c}\text { Do not know } \\
\text { answer }\end{array}$} \\
\hline & $\%$ & $95 \% \mathrm{Cl}$ & $\%$ & $95 \% \mathrm{Cl}$ & $\%$ & $95 \% \mathrm{Cl}$ \\
\hline 1. $\mathrm{CO}^{\mathrm{a}}$ can be detected by smoke & 21.6 & $15.0-28.3$ & 65.5 & $57.9-73.2$ & 12.8 & $7.4-18.2$ \\
\hline 2. CO can be detected by smell & 34.9 & $27.2-42.6$ & 53.0 & $45.0-61.0$ & 12.1 & $6.8-17.3$ \\
\hline 3. CO can be detected by an alarm & 87.2 & $81.8-92.6$ & 3.4 & $0.5-6.3$ & 9.5 & $4.7-14.2$ \\
\hline 4. CO can cause drowsiness & 77.2 & $70.4-83.9$ & 5.4 & $1.7-9.0$ & 17.4 & $11.4-23.5$ \\
\hline 5. CO can cause headaches & 81.9 & $75.7-88.1$ & 0.0 & $0.0-2.4$ & 18.1 & $11.9-24.3$ \\
\hline 6. CO can cause nausea & 77.2 & $70.4-83.9$ & 4.0 & $0.9-7.2$ & 18.8 & $12.5-25.1$ \\
\hline 7. CO can cause fainting & 75.8 & 69-82.7 & 4.7 & $1.3-8.1$ & 19.5 & $13.1-25.8$ \\
\hline 8. CO can cause convulsions & 54.4 & $46.4-62.4$ & 16.1 & $10.2-22.0$ & 29.5 & $22.2-36.9$ \\
\hline 9. CO can cause poisoning & 78.5 & $71.9-85.1$ & 6.0 & $2.2-9.9$ & 15.4 & $9.6-21.2$ \\
\hline 10. CO can cause death & 88.6 & $83.5-93.7$ & 0.0 & $0.0-2.4$ & 11.4 & $6.3-16.5$ \\
\hline 11. CO alarms cost 100 pesos or less & 34.9 & $27.2-42.6$ & 37.6 & $29.8-45.4$ & 27.5 & $20.3-34.7$ \\
\hline \multicolumn{7}{|l|}{ 12. Heaters with oxygen depletion sensors } \\
\hline cost 1,000 pesos or less & 32.2 & $24.7-39.7$ & 43.6 & $35.7-51.6$ & 24.2 & $17.3-31.0$ \\
\hline 13. Electric heaters can generate $\mathrm{CO}$ & 49.7 & $41.6-57.7$ & 31.5 & $24.1-39.0$ & 18.8 & $12.5-25.1$ \\
\hline 14. Gas heaters can generate $\mathrm{CO}$ & 83.3 & $77.4-89.3$ & 2.0 & $0.7-5.7$ & 14.7 & $9.0-20.3$ \\
\hline 15. Stoves can generate $\mathrm{CO}$ & 81.2 & $74.9-87.5$ & 2.7 & $1.1-5.3$ & 16.1 & $10.2-22.0$ \\
\hline 16. Wood heaters generate $\mathrm{CO}$ & 78.0 & $71.4-84.6$ & 6.7 & $2.7-10.7$ & 15.3 & $9.6-21.1$ \\
\hline \multicolumn{7}{|l|}{ 17. CO alarm questions } \\
\hline Do you own a CO alarm? & 6.7 & $2.7-10.7$ & & & & \\
\hline Do you know someone using a $\mathrm{CO}$ alarm? & 23.5 & $16.7-30.3$ & & & & \\
\hline Do you know how to use a CO alarm? & 16.8 & $10.8-22.8$ & & & & \\
\hline
\end{tabular}

a CO, carbon monoxide.

and $65.5 \%$ believed that $\mathrm{CO}$ can be seen as smoke. These knowledge gaps may directly lead to risky behavior. While $87.2 \%$ are aware that alarms are available to detect $\mathrm{CO}$, only $6.7 \%$ own a $\mathrm{CO}$ detector, possibly because large majorities mistakenly believe that $\mathrm{CO}$ can be detected by other means (sight or smell). Other knowledge gaps that may hinder the use of CO alarms include that $65.1 \%$ of respondents either do not know the cost or overestimate the cost of an alarm and $83.2 \%$ are unsure how to use an alarm.

The third column of Table 1 summarizes the status of the knowledge gaps given the information gained from the baseline survey. Several potential knowledge gaps identified during the semistructured interviews were judged to be less critical based on the results of the baseline survey. While knowledge of the sources of $\mathrm{CO}$ was identified as a potential knowledge gap from the semistructured interviews, on the baseline survey a majority of respondents identified gas heaters, wood heaters, and stoves as sources of CO (questions 13-16). Similarly, more knowledge about nonacute symptoms of $\mathrm{CO}$ poisoning (questions 5-7) and the potentially fatal nature of $\mathrm{CO}$ intoxication (question 10) was found on the baseline survey than in the semistructured interviews. These differences are probably due to the different formats of the two surveys. The semistructured interviews did not contain prompts for these pieces of information and therefore would elicit only information readily recalled to memory. Because the baseline survey prompted respondents for spe- cific knowledge, it identified knowledge that was less readily recalled to memory.

Some potential knowledge gaps identified during the semistructured interviews were confirmed by the baseline survey. While a large majority of respondents were aware of $\mathrm{CO}$ detectors, several important misconceptions (as discussed above) were identified. The baseline survey also substantiated a knowledge gap with respect to oxygen depletion sensors, as $67.8 \%$ either stated that they did not know the cost or overestimated the cost of a heater with an oxygen depletion sensor.

Table 4 indicates major misconceptions found on the baseline survey, by gender. Only $13.5 \%$ of respondents correctly knew all three of the following: (1) one cannot smell $\mathrm{CO}$, (2) $\mathrm{CO}$ is not smoke

TABLE 4. Fraction of respondents giving correct answers on baseline survey by gender ( $n=148)$, Mexico, 2005-2006

\begin{tabular}{|c|c|c|c|c|c|c|c|}
\hline \multirow[b]{3}{*}{ Question } & \multicolumn{6}{|c|}{ Correct answers } & \multirow{3}{*}{$\begin{array}{l}\text { Significance of } \\
\text { difference between } \\
\text { males and females } \\
\left(P \text { value for } \chi^{2} \text { test }\right)\end{array}$} \\
\hline & \multicolumn{2}{|c|}{ Males } & \multicolumn{2}{|c|}{ Females } & \multicolumn{2}{|c|}{ Overall } & \\
\hline & $\%$ & $95 \% \mathrm{Cl}$ & $\%$ & $95 \% \mathrm{Cl}$ & $\%$ & $95 \% \mathrm{Cl}$ & \\
\hline Can smella & 45.8 & $35.9-55.8$ & 20.6 & $7.0-34.2$ & 39.2 & $30.8-47.6$ & 0.010 \\
\hline Can detect with an alarm & 85.5 & $78.9-92.0$ & 89 & $79.7-98.5$ & 86.5 & $81.0-92.0$ & 0.53 \\
\hline Can see (as smoke) & 25.5 & $17.3-33.6$ & 10.5 & $2.5-20.3$ & 21.6 & $15.0-28.3$ & 0.054 \\
\hline Answered all three questions correctly & 17.3 & $10.2-24.3$ & 2.6 & $0.6-7.7$ & 13.5 & $8.0-19.0$ & 0.023 \\
\hline
\end{tabular}

a 130 valid responses. 
and cannot be seen, and (3) alarms can detect $\mathrm{CO}$. Women were significantly less knowledgeable than men, with only $2.6 \%$ of women ( 1 of the 38 surveyed) responding accurately on all three points, compared with $17.3 \%$ of men (19 of 110 surveyed, $p=0.023$ for a $\chi^{2}$ test). This difference may point to a need for informational campaigns directed at women, particularly as women often make household purchases.

The baseline survey found that many residents were already aware of and practiced some safety measures. More than $90 \%$ used blankets at times rather than running a heater, opened windows when heaters were on, and turned off the heater before going to bed (light gray bars in Figure 4). Safety measures such as these that are already being practiced do not need to be emphasized in the communication protocol.

For each of these safety measures, a follow-up question asked if respondents would be willing to undertake the measure in the future (black bars in Figure 4). A positive response in no way guarantees that the subjects will actually adopt the safety measure but at least provides a baseline assessment of the willingness of the target population to undertake various behavioral changes. The strategy here was to look for a safety measure with a large gap between the top of the gray bar and the top of the black bar; this is a safety measure that is not currently being practiced but for which there is a high expressed willingness to adopt the measure. By stressing these types of behaviors, a risk communication protocol will avoid needlessly advocating measures that are already being practiced and will focus on measures that are not being adopted but that appear to be attractive to the subject population. (Note that prospective measures should also be vetted against the expert model to verify that they are effective.)

Heaters with oxygen sensors and $\mathrm{CO}$ alarms are the most infrequently used safety precautions $(20.1 \%$ and $6.7 \%$, respectively) but a very high number of participants are willing to use them (71.8\% and $67.1 \%$, respectively). Both these mitigation strategies were therefore included in the comic book. CO alarms were emphasized somewhat over the use of heaters with oxygen sensors because the alarms are far less costly than new heaters (costing roughly 100 pesos compared with 1000 pesos for a new heater).

A number of other mitigation strategies-using blankets to minimize use of the heater, turning off the heater before going to sleep, and opening windowswere reported to be in use by large majorities of the population ( $>90 \%)$. Checking the color of the flame and having a technician check the heater were less widely practiced $(72.7 \%$ and $38.0 \%$, respectively). The effectiveness of many of these approaches is open to question. A study of a U.S. population suggests that individuals place too much confidence in ventilation as a means of reducing $\mathrm{CO}$ exposure (27). Checking the color of the flame and having a technician check the heater seemed to have limited potential for expanded use, as only a small proportion of respondents were not practicing these safety measures and reported being willing to adopt them $(14.1 \%$ and $27.5 \%$, respectively).

\section{Risk communication instrument development and evaluation}

The data derived from the baseline survey and expert model were used to guide the development of the initial health communication comic book. The fourth column of Table 1 describes the prioritization given to the five elements identified as potentially important. Given that important misconceptions were identified about the use of CO detectors $(86.5 \%$ answered at least one of the questions in Table 4 incorrectly), this element was given the highest priority. In the storyline of the comic book, the purchase of a $\mathrm{CO}$ detector was presented as the solution to the problem of the hazard posed by $\mathrm{CO}$, and a specific recommendation was made for the use of alarms at the close of the comic book. Survey participants also had important knowledge gaps relating to the potential use of heaters with oxygen-depletion sensors (only $32.2 \%$ knew that these items were available for less than 1000 pesos). This was mentioned in the comic book but

FIGURE 4. Fraction of respondents currently practicing and willing to practice safety measures. Size of gap between gray and black bars is proposed as an assessment metric for the measures' potential for increased adoption, Mexico, 2005-2006

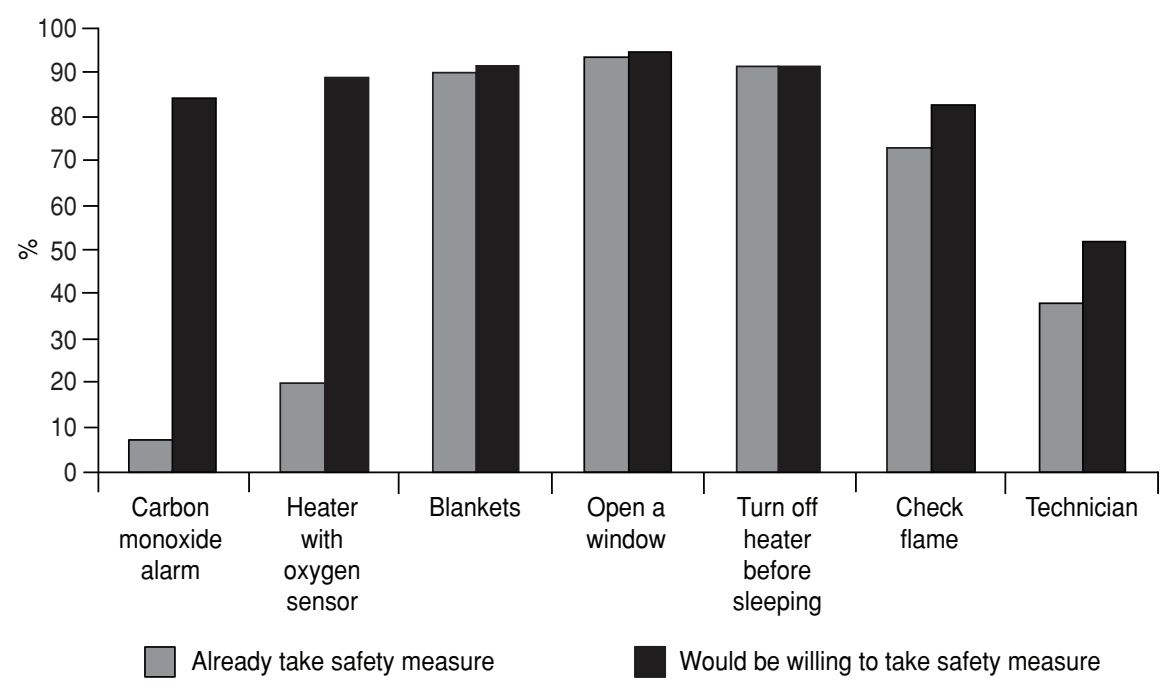


not stressed, because the alarms offered a more cost-effective solution. Most participants did have knowledge of nonacute symptoms, based on the results of the baseline survey (questions 4-9 in Table 3). This knowledge may not have been readily recalled to memory, as it was mentioned rather infrequently during the semistructured interviews, but it was recalled when respondents were offered the prompt of a specific question. These symptoms were mentioned in the course of the narrative to increase the availability of this information and to inform the minority of respondents who were not aware of these symptoms. Participants generally had acceptable knowledge of the sources of CO (questions 14-16 in Table 3). It was natural to mention the sources of $\mathrm{CO}$ during the course of the comic book narrative, but it was not a key point that was emphasized. The vast majority of participants were already aware of the potentially fatal aspects of $\mathrm{CO}$ (question 10 in Table 3 ), and it was not stressed in the comic book (although it was certainly implied by the title The Invisible Assassin).

The comic book was then evaluated by using a pretest/posttest. Demographic information on participants in the pretest/posttest evaluation is shown in Table 2. The sample had reasonable gender balance ( $43.0 \%$ females and $57.0 \%$ males) and included a range of educational backgrounds $(28.0 \%$ elementary school only, $22.0 \%$ college educated). Most participants were fairly young $(56.0 \%$ below 30 years of age).

The results of this evaluation are shown in Table 5. General knowledge about $\mathrm{CO}$ increased when comparing pretest and posttest answers. For example, only $41.0 \%$ correctly identified $\mathrm{CO}$ as a gas before reading the comic book, while $80.0 \%$ did so after reading it
( $p<0.01$ for $\chi^{2}$ test of proportions). Before reading the comic book, $21.0 \%$ mistakenly believed $\mathrm{CO}$ could be detected by scent, and only $2.0 \%$ still believed so posttest $(p<0.01)$. An increase to $88.0 \%$ (from a pretest value of $67.0 \%$ ) was found when participants were asked if sensors on heaters would help lower the risk of $\mathrm{CO}$ poisoning in the home $(p<0.01)$.

A significant increase $(p<0.01)$ in the awareness of $\mathrm{CO}$ poisoning as a health concern was found when participants were asked if $\mathrm{CO}$ poisoning would cause nausea, fainting, or headaches. Also, $\mathrm{CO}$ was identified to be a poison significantly more frequently ( $p=0.018)$ when participants were questioned after reading the information provided. Because 98.0\% knew CO could cause death before they read the comic book, a significant increase was not found, but there was a slight increase to $99.0 \%$ in the posttest survey $(p=0.561)$.

TABLE 5. Results of pretest and posttest surveys ( $n=100$ ), Mexico, 2006-2007

\begin{tabular}{|c|c|c|c|c|c|}
\hline \multirow[b]{3}{*}{ Question } & \multicolumn{4}{|c|}{ Answering yes } & \multirow{3}{*}{$\begin{array}{c}\text { Significance } \\
\text { of change, } \\
P \text { value }\end{array}$} \\
\hline & \multicolumn{2}{|c|}{ Pretest } & \multicolumn{2}{|c|}{ Posttest } & \\
\hline & $\%$ & $95 \% \mathrm{Cl}$ & $\%$ & $95 \% \mathrm{Cl}$ & \\
\hline \multicolumn{6}{|l|}{ Knowledge } \\
\hline 1. CO is a gas ${ }^{a}$ & 41.0 & $31.4-50.6$ & 80.0 & $72.2-87.8$ & $<0.01^{b}$ \\
\hline 2. $\mathrm{CO}$ is generated when something is burned & 31.0 & $21.9-40.1$ & 68.0 & $58.9-77.1$ & $<0.01^{b}$ \\
\hline 3. Gas heaters generate $\mathrm{CO}$ & 84.0 & $76.8-91.2$ & 96.0 & $92.2-99.8$ & $<0.01^{b}$ \\
\hline 4. Wood heaters generate $\mathrm{CO}$ & 52.0 & $42.2-61.8$ & 62.0 & $52.5-71.5$ & 0.15 \\
\hline 5. Electric heaters generate $\mathrm{CO}$ & 8.0 & $2.7-13.3$ & 8.0 & $2.7-13.3$ & 1 \\
\hline 6. Heating generates $\mathrm{CO}$ & 34.0 & $24.7-43.3$ & 37.0 & $27.5-46.5$ & 0.66 \\
\hline 7. Gas stoves generate $\mathrm{CO}$ & 51.0 & $41.2-60.8$ & 70.0 & $61.0-79.0$ & $<0.01^{b}$ \\
\hline 8. Wood stoves generate $\mathrm{CO}$ & 31.0 & $21.9-40.1$ & 37.0 & $27.5-46.5$ & 0.37 \\
\hline 9. Electric stoves generate $\mathrm{CO}$ & 3.0 & $1.1-6.3$ & 3.0 & $1.1-6.3$ & 1 \\
\hline 10. Roasters generate $\mathrm{CO}$ & 13.0 & $6.4-19.6$ & 17.0 & $9.6-24.4$ & 0.43 \\
\hline 11. I don't know what generates CO & 6.0 & $1.3-10.7$ & 1.0 & $0.2-3.0$ & $0.05^{b}$ \\
\hline 12. $\mathrm{CO}$ is detected with a $\mathrm{CO}$ alarm & 29.0 & $20.1-37.9$ & 86.0 & $79.2-92.8$ & $<0.01^{b}$ \\
\hline 13. CO can be detected by scent & 21.0 & $13.0-29.0$ & 2.0 & $0.6-4.7$ & $<0.01^{b}$ \\
\hline 14. $\mathrm{CO}$ is detected with a smoke alarm & 5.0 & $2.2-9.3$ & 8.0 & $2.7-13.3$ & 0.39 \\
\hline 15. CO can cause headache & 90.0 & $84.1-95.9$ & 99.0 & $97.0-100.0$ & $<0.01^{b}$ \\
\hline 16. CO can cause nausea & 72.0 & $63.2-80.8$ & 94.0 & $89.3-98.7$ & $<0.01^{b}$ \\
\hline 17. CO can cause fainting & 78.0 & $69.99-86.1$ & 92.0 & $86.7-97.3$ & $<0.01^{b}$ \\
\hline 18. CO can cause poison & 85.0 & 78.0-92.0 & 95.0 & $90.7-99.3$ & $0.02^{b}$ \\
\hline 19. CO can cause death & 98.0 & $95.3-99.8$ & 99.0 & $97.0-100.0$ & 0.56 \\
\hline 20. I already know how to use a CO alarm & 20.0 & $12.2-27.8$ & 76.0 & $67.6-84.4$ & $<0.01^{b}$ \\
\hline 21. A CO alarm costs 100 pesos & 11.0 & $4.9-17.1$ & 30.0 & $21.0-39.0$ & $<0.01^{b}$ \\
\hline 22. I can buy a $\mathrm{CO}$ alarm in the supermarket & 33.0 & $23.8-42.2$ & 76.0 & $67.6-84.4$ & $<0.01^{b}$ \\
\hline \multicolumn{6}{|l|}{ Attitude } \\
\hline 23. A CO alarm would protect my home & 76.0 & $67.6-84.4$ & 91.0 & $85.4-96.6$ & $<0.01^{b}$ \\
\hline 24. A heater with sensor would protect my home & 67.0 & $57.8-76.2$ & 88.0 & $81.6-94.4$ & $<0.01^{b}$ \\
\hline \multicolumn{6}{|l|}{ Intended practice/would make change } \\
\hline 25. I am willing to install a CO alarm at my home & 70.0 & $61.0-79.0$ & 89.0 & $82.9-95.1$ & $<0.01^{b}$ \\
\hline 26. I am willing to turn off the heaters during the night & 94.0 & $89.3-98.7$ & 97.0 & $93.7-99.4$ & 0.31 \\
\hline 27. I am willing to install metal hoses & 79.0 & $71.0-87.0$ & 92.0 & $86.7-97.3$ & $<0.01^{b}$ \\
\hline 28. I am willing to open two windows when the heaters are on & 95.0 & $90.7-99.3$ & 98.0 & $95.3-99.8$ & 0.25 \\
\hline 29. I am willing to change to a heater with a sensor & 73.0 & $64.3-81.7$ & 89.0 & $82.9-95.1$ & $<0.01^{b}$ \\
\hline
\end{tabular}

${ }^{a} \mathrm{CO}$, carbon monoxide.

${ }^{b}$ Statistically significant difference between pretest and posttest by $\chi^{2}$ test $(p<0.05)$. 
The principal goal of the comic book, increasing knowledge of $\mathrm{CO}$ alarms, appears to have been accomplished. Only $29.0 \%$ of those surveyed before reading the comic book were aware $\mathrm{CO}$ could be detected by a $\mathrm{CO}$ alarm. However, after reading the comic book, $86.0 \%$ of participants knew it $(p<0.01)$. The percentage of respondents stating that they knew how to use a $\mathrm{CO}$ alarm increased from $20.0 \%$ to $76.0 \%(p<0.01)$, and those conscious that a $\mathrm{CO}$ alarm could protect their homes increased from $76.0 \%$ to 91.0\% $(p<0.01)$. Knowledge of CO alarm price (100 pesos) and availability in supermarkets also increased significantly $(p<0.01)$. A significant increase in those expressing willingness to install $\mathrm{CO}$ alarms $(70.0 \%$ pretest, $89.0 \%$ posttest, $p<0.01$ ) was found, perhaps due to improved technical understanding.

The sources of $\mathrm{CO}$ were more readily identified by participants after reading the comic book. Significant increases $(p<0.01)$ were found when comparing pretest and posttest results of questions asking if $\mathrm{CO}$ is generated when something is burned and if it is generated by a gas heater and a gas stove. There was a slight, nonsignificant increase in the percentage identifying wood heaters; gas, wood, and electric stoves; and roasters as sources of CO (compared with pretest responses). Although only a small amount $(6.0 \%)$ did not know what generated $\mathrm{CO}$ on the pretest, only $1.0 \%$ surveyed after reading the comic book answered that they did not know ( $p=0.054)$.

In many cases, high percentages of respondents indicated a willingness to implement $\mathrm{CO}$ risk-reduction measures on the pretest, making it difficult for it to increase significantly on the posttest. For example, $94.0 \%$ of respondents were already willing to turn off heaters during the night before studying the comic book. While this tendency increased to 97.0\% posttest, the increase was not statistically significant $(p=0.306)$. Similarly, posttest results show that $98.0 \%$ of those asked were willing to open windows when heaters are on, which was not statistically significantly elevated from the pretest value of $95.0 \%(p=0.248)$. Significant increases were found $(p<0.01)$ when participants were asked if they were willing to install metal hoses (increase from $79.0 \%$ to $92.0 \%$ ) or change to a heater with a sensor $(73.0 \%$ to $89.0 \%)$. Most importantly, willingness to use CO alarms, the key behavioral change targeted by the comic book, increased from $70.0 \%$ to $89.0 \%(p<0.01)$.

\section{DISCUSSION}

This study constitutes the first successful report of applying the mental models process to develop a health-risk communication for a low socioeconomic status Latino population. The study was able to identify key knowledge gaps that were prevalent in the target population, including understanding the need for $\mathrm{CO}$ alarms (because $\mathrm{CO}$ cannot be seen or smelled) and the low cost of CO alarms. These knowledge gaps suggest an interventional strategy, encouraging the purchase and use of $\mathrm{CO}$ alarms. CO alarms were also selected as an interventional strategy because (1) they are not commonly used at present and (2) most survey participants expressed a willingness to use them. A comic book designed to improve knowledge about $\mathrm{CO}$ risks was successful in improving the knowledge of individuals participating in a pretest/ posttest evaluation.

The successful identification of conceptual understanding and knowledge gaps has been demonstrated by a large number of previous mental model studies spanning almost two decades (see Morgan et al. (12) for discussion of many studies up to 2002; more recent applications include Wilson et al. (28), Downs et al. (29), and Wagner (30)). While there have been many studies using the mental models approach to risk communication, there are relatively few studies in which the risk communications instruments designed using the mental models approach are subjected to systematic evaluation, such as a pretest/posttest. The authors were able to locate only four such studies $(14,17,19) .6$ Three of the four previous studies obtained results similar to ours, where posttest results showed increased knowledge from the pretest: Read and Morgan (17), Maharik and Fischhoff (19), and Downs et al., ${ }^{6}$ which was described by Morgan et al. (12), all showed improvements, while Hampson et al. (14) failed to show improvement in a particularly difficult concept, synergistic risk.

This study was the first to apply the mental models framework to identify key misunderstandings about CO risk. Previous studies of public comprehension about this risk are surprisingly rare for such a common cause of intoxication. Only one previous study, a brief report by Greife et al. (27), could be located. Griefe et al. concluded that many subjects placed too much confidence in ventilation as an exposure reduction measure. The results presented here also indicate that many participants relied on ventilation to reduce exposure to $\mathrm{CO}$. No previous reports on misconceptions as to the need for and cost of $\mathrm{CO}$ alarms could be found, and further research is needed to assess how common the knowledge gaps identified here are in other populations.

\section{Limitations}

Because participants were asked the same questions pretest and posttest, they may have been more inclined to remember topics that the initial questionnaire focused on. However, a previous study found that answering questions about the topic before reading the informational materials did not significantly increase learning (31). Because a convenience sample was used, the sample was likely not perfectly representative of the population of Ciudad Juárez. However, the sample did contain a large percentage of respondents using unvented indoor combustion appliances and therefore represents a population of interest for this study. The authors believe these results are an appropriate basis on which to design a communitywide intervention on a preliminary basis. Mexicans immigrating to the United States are particularly at risk for $\mathrm{CO}$ poisoning (32) and may be an important target group for such interventions. A free copy of the comic book developed here is available online (http://coprojectjuarez. wikispaces.com). The intervention should be evaluated and revised on an ongoing basis so that it more effectively reaches any community members not well represented by this initial study.

\section{Conclusions}

Greater awareness of and use of CO alarms was identified as an appropriate behavioral change to reduce $\mathrm{CO}$ intoxication risk. The widespread beliefs that $\mathrm{CO}$ can be seen or smelled and lack of knowledge of the affordability and need for $\mathrm{CO}$ alarms were identified as the knowledge gaps hindering adoption of the desired behavioral change. A risk 
communication instrument was developed and found to be successful at addressing these knowledge gaps in a pretest/posttest evaluation.

\section{Recommendations}

The fact that the mental models approach appears to work well in providing technological information for a lower socioeconomic status, Latino population is encouraging. Nevertheless, no single study can establish that the mental models framework is more effective than potential alternative approaches. A meta- analysis would be required for this and once a sufficient number of published studies are available, undertaking such a meta-analysis would be warranted.

While this study showed that knowledge improved immediately after reading the risk communication instrument, further research is needed to assess how well this information is retained over time. Furthermore, it is well known that improving knowledge does not guarantee behavioral change. Additional research is clearly needed to assess how frequently the behavioral modifications, which are recommended by the risk com- munication protocol developed here, are actually implemented. As this study used a convenience sample, the results are preliminary and further efforts are needed to identify population groups that are at risk from $\mathrm{CO}$ and have different information needs from the participants in this study.

Future efforts to reduce $\mathrm{CO}$ intoxications should consider undertaking risk communication efforts directed at increasing the use of $\mathrm{CO}$ alarms. The comic book risk communication instrument produced by this study is freely available and may be appropriate for use in such efforts.

\section{REFERENCES}

1. CBC News. New treatment for carbon monoxide poisoning. CBC News, 2000; November 10. Available from: http://www. cbc.ca/health/story/2000/06/16/carbon monoxide000616.html\#skip300x25. Accessed 10 January 2009.

2. Raub JA, Mathieu-Nolf M, Hampson NB, Thom SR. Carbon monoxide poisoning-a public health perspective. Toxicology. 2000; 145:1-14.

3. Mott JA, Wolfe MI, Alverson CJ, Macdonald SC, Bailey CR, Ball LB, et al. National vehicle emissions policies and practices and declining US carbon monoxide-related mortality. J Am Med Assoc. 2002;288(8):988-95.

4. Thom SR, Bhopale VM, Fisher D, Zhang J, Gimotty P. Delayed neuropathology after carbon monoxide poisoning is immunemediated. Proc Natl Acad Sci. 2004;101(37): 13660-5.

5. Jasper BW, Hopkins RO, VanDyker H, Weaver LK. Affective outcome following carbon monoxide poisoning: a prospective longitudinal study. Cogn Behav Neurol. 2005; 18(2):127-34.

6. Montoya T, Gurian PL, Velázquez-Angulo G, Corella-Barud V, Rojo A, Graham JP. Carbon monoxide exposure in households in Ciudad Juárez, México. Int J Hyg Environ Health. 2008;211(1-2):40-9.

7. Diario de Juárez. Calentadores mortales: un mal que se repite. Diario de Juárez. 4 January 2004.

8. Gurian PL, Montoya T, Corella-Barud V, Mulla ZD. Unintentional carbon monoxide poisoning cases in Ciudad Juárez, México. Southern Med J. 2005;98(9):955-6.

9. Graham JP, Corella-Barud V, Avilla R, Gurian PL. The in-home environment and household health: a cross-sectional study of informal urban settlements in northern Mexico. Int J Environ Res Public Health. 2005;2(3).

10. Graham JP, Gurian PL, Corella-Barud V, Avilla R. Periurbanization and in-home environmental health risks: the side effects of planned and unplanned growth. Int J Hyg Environ Health. 2004;207(5):447-54.
11. Rogers, EM. Diffusion of innovations. 5th ed. New York: Free Press; 2003.

12. Morgan MG, Fischhoff B, Bostrom A, Atman, CJ. Risk communication: a mental models approach. New York: Cambridge University Press; 2002.

13. Bostrom AM, Fischhoff B, Morgan MG. Characterizing mental models of hazardous processes: a methodology and an application to radon. J Social Issues. 1992;48(4):85-100.

14. Hampson SE, Andrews JA, Lee ME, Foster LS, Glasgow RE, Lichtenstein E. Lay understanding of synergistic risk: the case of radon and cigarette smoking. Risk Anal. 1998;18(3): $343-50$.

15. Hester G, Morgan MG, Nair I, Florig K. Small group studies of regulatory decision making for power-frequency electric and magnetic fields. Risk Anal. 1990;10(2):213-28.

16. Morgan MG, Florig HK, Nair I, Cortes C, Marsh K, Pavlosky K. Lay understanding of low-frequency electric and magnetic fields. Bioelectromagnetics. 1990;11(4):313-35.

17. Read D, Morgan GM. The efficacy of different methods for informing the public about the range dependency of magnetic fields from high voltage power lines. Risk Anal. 1998; 18(5):603-10.

18. Bostrom AM, Morgan G, Fischhoff B, Read D. What do people know about global climate change? 1. Mental models. Risk Anal. 1994; 14(6):959-70.

19. Maharik M, Fischhoff B. The risks of using nuclear energy sources in space: some lay activists' perceptions. Risk Anal. 1992;12(3): 383-92.

20. Hine D, Summers C, Tilleczek K, Lewko J. Expectancies and mental models and determinants of adolescents' smoking decisions. J Social Issues. 1997;53(1):35-52.

21. Cox P, Niewöhner J, Pidgeon N, Gerrard S, Fischhoff B, Riley D. The use of mental models in chemical risk protection: developing a generic workplace methodology. Risk Anal. 2003;23(2):311-24.

22. Zaksek M, Arvai JL. Toward improved communication about wildland fire: mental mod- els research to identify information needs for natural resource management. Risk Anal. 2004;24(6):1503-14.

23. Jungermann $H$, Schütz $H$, Thüring $M$. Mental models in risk assessment: informing people about drugs. Risk Anal. 1988;8(1):147-55.

24. Freimuth VS, Massett HA, Meltzer W. A descriptive analysis of 10 years of research published in the Journal of Health Communication. J Health Commun. 2006;11:11-20.

25. Airhihenbuwa CO, Obregon R. A critical assessment of theories/models used in health communication for HIV/AIDS. J Health Commun. 2000;5(suppl):5-15.

26. Gehan E. Clinical trials in cancer research. Environ Health Perspect. 1979:32:31-48.

27. Greife AL, Goldenhar LM, Freund E, Stock A, Halperin W. Carbon monoxide poisoning from gasoline-powered engines: risk perception among Midwest flood victims. Am J Public Health. 1997;87(3):466-7.

28. Wilson RS, Tucker MA, Hooker NH, LeJeune JT, Doohan D. Perceptions and beliefs about weed management: perspectives of Ohio grain and produce farmers. Weed Technol. 2008; 22(2):339-50.

29. Downs JS, de Bruin WB, Fischhoff B. Parents' vaccination comprehension and decisions. Vaccine. 2008;26(12):1595-607.

30. Wagner K. Mental models of flash floods and landslides. Risk Anal. 2007;27(3):671-82.

31. Bier VM. On the state of the art: risk communication to the public. Reliability Eng Syst Saf. 2001;71:139-50.

32. Council of State Governments. Hispanic communities face unique risks from their environment. Ecos. 2006; winter. Available from: http://www.healthystates.csg.org/NR/rdon lyres / 60336A35-D0F9-428A-8E4D-33D 117167AF1/0/CPEcosWinter069to11.pdf. Accessed 10 January 2009.

Manuscript received on 1 November 2007. Revised version accepted for publication on 10 August 2008. 
RESUMEN Objetivos. Los residentes de bajos ingresos del norte de México dependen durante el invierno de calefactores no ventilados, una práctica que los pone en mayor riesgo de intoxicación por monóxido de carbono. Se elaboró un protocolo de comunicación

Aplicación del enfoque de los modelos mentales al riesgo por monóxido de carbono en el norte de México sobre los riesgos de intoxicación por monóxido de carbono en la población fundamentalmente de bajo nivel socioeconómico de Ciudad Juárez, Chihuahua, México.

Métodos. Se utilizó el enfoque de comunicación de riesgos de los modelos mentales para identificar importantes brechas en la comprensión pública. Este enfoque consiste en la evaluación paso a paso de las necesidades de información y la eficacia de los esfuerzos de comunicación de riesgos, mediante entrevistas y encuestas.

Resultados. El proceso basado en los modelos mentales descubrió un malentendido técnico clave: la población estudiada cree que el monóxido de carbono se puede ver u oler. Esto puede llevar a un comportamiento proclive al riesgo: no utilizar detectores de monóxido de carbono. Se diseñó un protocolo de comunicación para atender esta y otras brechas en el conocimiento que, según las evaluaciones previa y posterior, mejoró significativamente el nivel de conocimiento de las personas.

Conclusiones. El proceso basado en modelos mentales permitió desarrollar exitosamente un instrumento de comunicación capaz de mejorar el nivel de conocimiento en la población estudiada. Investigaciones futuras deben evaluar en qué grado este instrumento logra modificar el comportamiento y reducir el riesgo de intoxicación por monóxido de carbono. Nuevas intervenciones podrían centrarse en estimular el uso de detectores de monóxido de carbono.

Palabras clave Monóxido de carbono, comunicación, control de riesgo, México. 